\title{
Editorial
}

\section{Resolving the Controversy on Environmental Cultures for Legionella: A Modest Proposal}

\author{
Victor L. Yu, MD
}

The two rigorous reports in this issue by investigators at the Centers for Disease Control and Prevention (CDC) make for exciting reading. ${ }^{1,2}$ These two reports demonstrate the importance of shoe-leather epidemiology, highlight the power of the new molecular biology with its subtyping capabilities, and deal with the drama of a disease that has, in the two hospitals described, a mortality of $35 \%$ to $40 \%$. When one reads Kool et al's description of the intense attempts to track down the source of the organism and the heroic effort to disinfect the water supply, it is no wonder that legionnaires' disease continues to command such attention 22 years after the outbreak at the 1976 American Legion Convention.

Are there any new lessons to be gleaned from these two reports? After all, the major conclusions in these two reports have been reiterated in numerous publications and are standard knowledge in medicine textbooks: they include the link to water distribution systems, the link to intubation and the possibility of aspiration; the recognition that the clinical presentation of legionnaires' disease is nonspecific, such that special laboratory tests are needed; and the high risk for contracting legionnaires' disease in transplant recipients and in patients administered corticosteroids. However, there are a number of salient points that illustrate the need for prevention, and I will focus on them.

What is remarkable to me is the number of outbreaks of hospital-acquired legionnaires' disease that still are occurring. How can this be after so many reports, dating back to 1982 , have linked the contamination of water distribution systems by Legionella to subsequent discovery of legionnaires' disease on the hospital ward? More reports with the same theme will be published in 1999. The epidemiological version of Koch's postulates ${ }^{3}$ have been fulfilled for linking Legionella colonization in hospital water supplies to hospital-acquired legionnaires' disease. ${ }^{4,5}$ (Koch's postulates have not been fulfilled for linking cooling tower reservoirs to legionnaires' disease). Since the reservoir for dissemination has been so well established, as in the two $\mathrm{CDC}$ reports in this issue, why have measures not been enacted to prevent this disease?

Pittsburgh investigators have recommended routine environmental cultures of the hospital water supply since 1986 , so as to screen for the possibility of occult legionnaires' disease in the hospital (Figures 1 and 2). 6 Obtaining surveillance cultures of water distribution systems in hospitals performing transplants is mandatory, in our opinion. 7,8 This is a proactive, scientifically based approach that is inexpensive and focuses attention on those patients and hospitals at the highest risk.

The two CDC articles both conclude that intensive surveillance for hospital-acquired legionellosis is necessary for prevention. Conspicuous by its absence is the alternative approach suggested by Pittsburgh investigators and mandated by the Allegheny County Health Department guidelines for prevention of Legionella infections ${ }^{9}$ (Figures 1 and 2). I am concerned that to perform patient surveillance without environmental cultures is to ignore the epidemiological data that have been collected by so many investigators, including the CDC. Knowledge of the reservoir for the organism can be applied to prevention! It

From the Veterans' Affairs Medical Center and University of Pittsburgh, Pittsburgh, Pennsylvania.

Address reprint requests to Victor L. Yu, MD, Infectious Disease Section, VA Medical Center, University Drive C, Pittsburgh, PA 15240.

98-ED-138. Yu VL. Resolving the controversy on environmental cultures for Legionella: a modest proposal. Infect Control Hosp Epidemiol 1998; 19:893-897. 


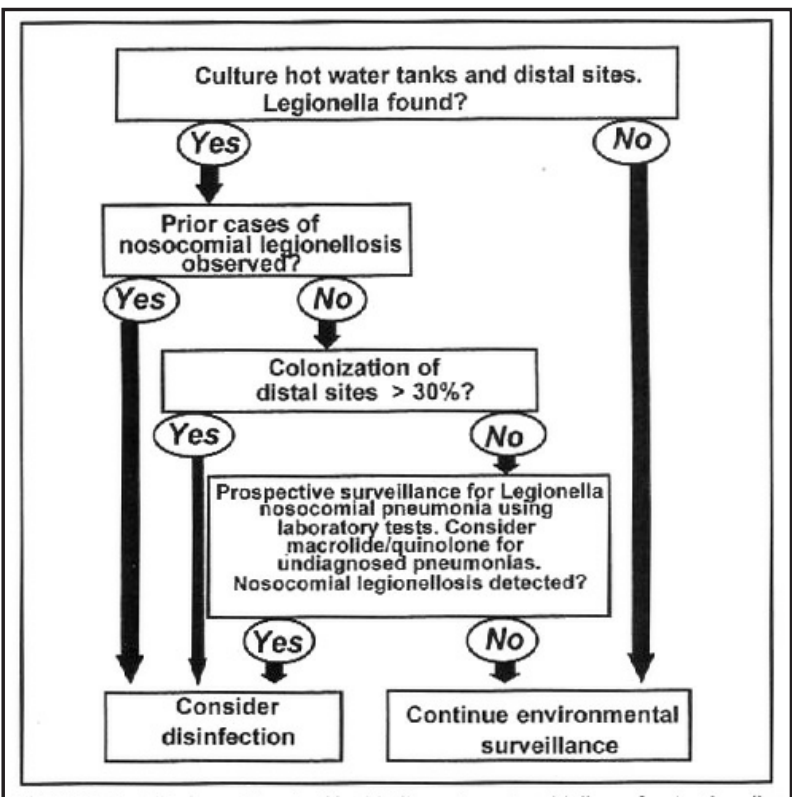

FIGURE 1. Allegheny County Health Department guidelines for Legionella environmental cultures and surveillance. ${ }^{9}$

makes little sense to me to initiate environmental cultures after cases of hospital-acquired legionnaires' disease have been discovered, as recommended by the CDC. Lepine et al make the telling points that hospital-acquired legionellosis rarely is an isolated event and that the discovery of a single case suggests that previous cases have been overlooked. ${ }^{2}$ Kool et al, note that the discovery of legionnaires' disease in their hospital was triggered by routine examination of autopsy lung specimens for Legionella in eight patients who died; this is hardly an elegant approach for preventing legionnaires' disease. ${ }^{1}$

If the water system is free of Legionella, positive tests for Legionella from inpatient specimens will approach zero (if a positive culture occurs, it is likely that the patient was a transfer from another hospital or a patient with communityacquired pneumonia that was overlooked). In hospitals in North Carolina and Minnesota in which Legionella could not be isolated from the water supply, no cases of hospitalacquired legionnaires' disease were uncovered despite intensive surveillance (VLY, unpublished data, 1993). In four controlled studies comparing legionnaires' disease attack rates in colonized versus noncolonized hospitals, hospital-acquired legionnaires' disease did not occur if Legionella was absent from the water supply. ${ }^{5,10-12}$ As a stark example, if one took CDC recommendations literally, that all hospitals initiate intensive surveillance without knowledge of the colonization status of Legionella within the water supply, 500 to 1,500 sputum cultures a year for Legionella could be obtained from hospitalized patients, depending on bed size, and all of these cultures would be negative. Thus, we advocate applying Legionella tests for hospital-acquired pneumonia only in patients residing in hospitals colonized with Legionella, so as to derive a reasonable yield. This is a common-sense approach for a fis-

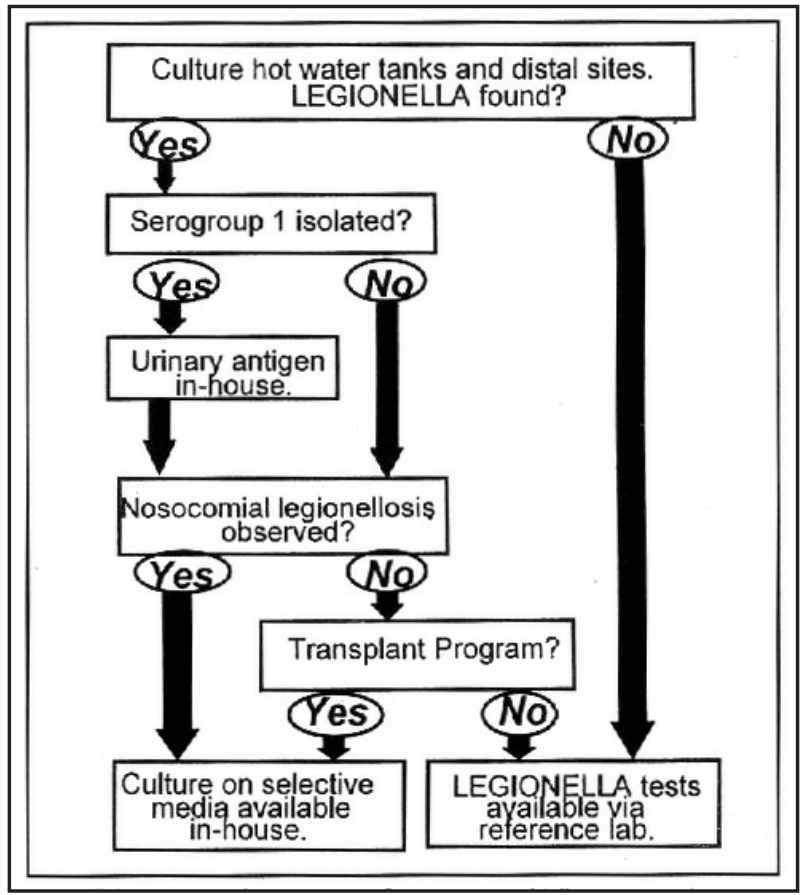

FIGURE 2. Allegheny County Health Department guidelines concerning capabilities for Legionella laboratory testing for patients. ${ }^{9}$

cally conscious era in which laboratory resources must be conserved carefully.

One reason given by the $\mathrm{CDC}$ for not recommending routine environmental cultures is the oft-cited claim that Legionella colonization is ubiquitous; the implication is that virtually all hospital water supplies are colonized by Legionella. However, this inference is refuted in six environmental surveys from Canada, the United States, and the United Kingdom (Table 1), as well as the studies the CDC has cited in Table 2. The proportion of hospitals colonized with Legionella ranged from $12 \%$ to $70 \%$ (Table 1$)^{8,13-16 \text {; }}$ thus, the organism is not ubiquitous in hospital water supplies. Differing environmental factors, especially temperature of the hot water, affect colonization of Legionella in hospital water distribution systems. $8,14,15,17$

CDC spokesmen repeatedly have stated that Legionella can colonize water distribution systems without causing disease, implying that colonization in water is not associated with disease in inpatients. ${ }^{18,19}$ This implication, if true, is a powerful argument against obtaining routine cultures of hospital water supplies. Thus, it becomes critical to review the data that support this assertion. The articles most frequently cited by the CDC to support this contention are listed in Table 2. In two studies, case finding for legionnaires' disease was not pursued, and the duration of follow-up was extremely limited. ${ }^{20,21}$ These studies, by Tobin et al and Dennis et al, were not designed to assess the risk of legionnaires' disease in hospitalized patients. Instead, they were surveys of hotels or hospitals (interestingly, only $20 \%$ to $30 \%$ of buildings sampled yielded Legionella pneumophila). No case finding was performed, 
TABLE 1

Hospital Surveys for Legionella Contamination of Water Distribution Systems

\begin{tabular}{|c|c|c|c|c|}
\hline Reference & Location & Hospitals & \% With Legionella & Isolate \\
\hline HMSO $^{13}$ & United Kingdom & 40 & $70 \%$ & $\begin{array}{l}\text { Legionella pneumophila, } \\
\text { serogroup } 1\end{array}$ \\
\hline Alary 14 & Quebec & 84 & $68 \%$ & $\begin{array}{l}\text { L pneumophila, } \\
\text { serogroups } 1-8\end{array}$ \\
\hline Vickers 15 & Western Pennsylvania & 15 & $60 \%$ & $\begin{array}{l}\text { L pneumophila, } \\
\text { serogroups } 1-6\end{array}$ \\
\hline Patterson 8 & United Kingdom & 69 & $55 \%$ & $\begin{array}{l}\text { L pneumophila, } \\
\text { Legionella species }\end{array}$ \\
\hline Marrie $^{16}$ & Nova Scotia & 39 & $23 \%$ & $\begin{array}{l}\text { L pneumophila } \\
\text { Legionella longbeachae }\end{array}$ \\
\hline $\mathrm{Liu}^{31}$ & United Kingdom & 17 & $12 \%$ & $\begin{array}{l}L \text { pneumophila, } \\
\text { serogroups } 1,4,6\end{array}$ \\
\hline
\end{tabular}

and diagnostic tests for Legionella were not employed in any patients! The Alary and Joly study was also a survey, in which Legionella was found in $68 \%$ of the hospitals studied (Table 2). ${ }^{14}$ Of note, in a follow-up of 20 hospitals in a subsequent case-control study (10 hospitals with Legionella colonization and 10 without Legionella colonization), the same authors found that "hospitals with a water supply contaminated by Legionella were more likely to have cases of legionellosis ( $P=.054$; Table 3$)$."11

In the CDC "Guidelines for Prevention of Nosocomial Pneumonia," 19 the study by Marrie et $\mathrm{al}^{22}$ is explicitly cited: "no cases of legionellosis occurred in a urology ward during a 3.5-month period when $70 \%$ of water samples were culture-positive for L pneumophila.” However, that 52 cases of legionnaires' disease were found in that same hospital on the other wards was not mentioned in the CDC guidelines. ${ }^{19,22}$ In a 1982 survey of the University of Pittsburgh teaching hospitals (Montefiore, Presbyterian University Hospital, Eye and Ear Hospital, Children's Hospital), high colonization rates were reported without the presence of disease, and the authors concluded that "existence of these bacteria in the plumbing systems and tanks was not necessarily associated with disease." 23 However, all of the hospitals experienced outbreaks within several years thereafter, with the total number of cases exceeding 100.5,24-26 Persistent clinical surveillance, with Legionella laboratory testing in patients with hospital-acquired pneumonia and follow-up for several years, was necessary to uncover these cases.

This issue has been argued by Pittsburgh investigators and the CDC for years, culminating in a debate at the 1996 annual meeting of the Society for Healthcare Epidemiology of America. 27 In science, legitimate differences of opinion should be resolved by further studies with improved focus and greater rigor. With apologies to Jonathan Swift, I suggest a modest proposal. A large-scale, prospective, observational study of the number of cases of hospital-acquired legionnaires' disease occurring in hospitals colonized with Legionella versus hospitals not colo-
TABLE 2

Literature Cited as Evidence That Colonization by LEGIONELLA Is Not Associated With Hospital-ACQUired LEGIONNAIRES' DisEASE

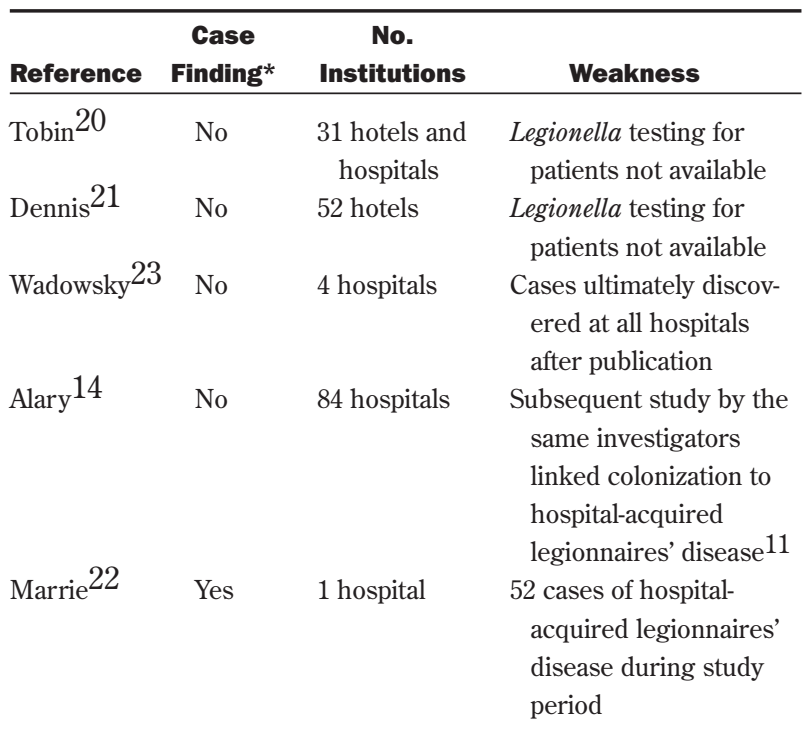

* Surveillance for patients with hospital-acquired pneumonia using laboratory methodology for Legionella.

nized with Legionella is in order. Some might argue that doing nothing in hospitals colonized with Legionella is unethical and unconscionable, but this is, in fact, the current state of the art. Virtually all authorities on legionnaires' disease have accepted the CDC viewpoint (to our chagrin). Thus, observing the natural outcome of hospitals colonized with Legionella in a controlled study would not affect the public health.

However, adherence to the Allegheny County Health Guidelines (Figures 1 and 2) can minimize morbidity and mortality. Once suspicion is raised, one can take advantage of the fact that legionnaires' disease is readily treatable; macrolides and quinolones can be used to treat hospital- 
TABLE 3

Prospective Studies in Which Hospital-Acquired Legionnaires' Disease Was Discovered After Initiating Clinical Surveillance Based on Positive Environmental Cultures

\begin{tabular}{|c|c|c|c|c|c|}
\hline Reference & Location & Hospitals & $\begin{array}{c}\text { Colonization }{ }^{*} \\
\text { (\% of Sites Positive) }\end{array}$ & No. of Cases & $\begin{array}{c}\text { Study } \\
\text { Duration }\end{array}$ \\
\hline Muder 32 & Pittsburgh & $\begin{array}{l}\text { Mercy Hospital } \\
\text { VA hospital }\end{array}$ & $\begin{array}{l}\text { Yes }(64 \%) \\
\text { Yes }(65 \%)\end{array}$ & $\begin{array}{l}6^{\dagger} \\
15^{\dagger}\end{array}$ & $3 \mathrm{mo}$ \\
\hline Rudin 24 & Pittsburgh & Montefiore Hospital & Yes (NA) & $6^{\dagger}$ & $5 \mathrm{mo}$ \\
\hline Johnson $^{5}$ & Pittsburgh & $\begin{array}{l}\text { Eye and Ear } \\
\text { Eye and Ear post-disinfection } \\
\text { VA hospital }\end{array}$ & $\begin{array}{l}\text { Yes }(67 \%) \\
\text { Yes }(3.5 \%) \\
\text { No }(0)\end{array}$ & $\begin{array}{l}8 \\
0 \\
0\end{array}$ & $\begin{array}{l}6 \mathrm{mo} \\
6 \mathrm{mo} \\
12 \mathrm{mo}\end{array}$ \\
\hline $\mathrm{Yu}^{10}$ & $\begin{array}{l}\text { Pittsburgh } \\
\text { Buffalo }\end{array}$ & $\begin{array}{l}2 \text { hospitals } \\
\text { VA hospital }\end{array}$ & $\begin{array}{l}\text { Yes }(2 \%-22 \%)^{\ddagger} \\
\text { Yes }(18 \%)\end{array}$ & $\begin{array}{l}0 \\
3\end{array}$ & $12 \mathrm{mo}$ \\
\hline Joly 11 & Quebec & $\begin{array}{l}10 \text { case hospitals } \\
10 \text { control hospitals }\end{array}$ & $\begin{array}{l}\text { Yes (NA) } \\
\text { No }(0)\end{array}$ & $\begin{array}{l}4 \text { in } 4 \text { hospitals } \\
0\end{array}$ & $9 \mathrm{mo}$ \\
\hline $\begin{array}{l}\text { Goetz }^{28} \\
\text { Modol }^{12}\end{array}$ & $\begin{array}{l}\text { Pittsburgh } \\
\text { Catalonia }\end{array}$ & $\begin{array}{l}4 \text { hospitals } \\
16 \text { hospitals } \\
4 \text { hospitals }\end{array}$ & $\begin{array}{l}\text { Yes }(10 \%-30 \%) \\
\text { Yes }(12.5 \%-100 \%) \\
\text { No }(0)\end{array}$ & $\begin{array}{l}12 \text { in } 3 \text { hospitals } \\
20 \text { in } 3 \text { hospitals } \\
0\end{array}$ & $\begin{array}{l}12 \text { mo } \\
\text { Ongoing }\end{array}$ \\
\hline
\end{tabular}

Abbreviations: NA, not available; VA, Veterans' Affairs.

* Water system colonized by Legionella pneumophila.

$\uparrow$ Includes cases of Legionella micdadei.

¥ Twenty-two percent of distal sites positive for Legionella pneumophila, serogroup 5.

acquired pneumonias of uncertain etiology. A low frequency of site contamination does not necessarily require disinfection (Figure 1). Many Pittsburgh hospitals with minimal contamination have elected not to disinfect the water supply but to treat infected patients if encountered. ${ }^{28}$ If the level of contamination increases, the option to disinfect the water supply can be exercised.

This issue of Infection Control and Hospital Epidemiology also provides an important report by Stout et al, of a cost-effective approach to disinfection. ${ }^{29}$ In the past, knowledge of Legionella colonization meant the tedious application of superheat and flush, as vividly described in the Kool et al report, or hyperchlorination with its attendant disadvantages of corrosion, expense, and erratic efficacy. (In the Kool et al report, the lack of success with the superheat-and-flush method can be attributed to flushing with hot water at $160^{\circ} \mathrm{F}$ for only 10 minutes instead of the recommended 30-minute duration ${ }^{30}$ ). Copper-silver ionization systems now have been installed in more than 75 US hospitals at the time of this writing; all three hospitals described in this issue of Infection Control and Hospital Epidemiology, including the hospital in the Kool et al report, have adopted such systems (Liqui-Tech, Willowbrook, IL). So, technology not only has improved our diagnostic capability and our ability to make epidemiological links but it also has furnished us with a viable solution.

What should hospital epidemiologists and infection control professionals do today while awaiting the ideal controlled study? I recommend that each hospital initiate their own observational study. As Goetz et al found in their study, "Seek and ye shall find." 28 The approach shown in Figures 1 and 2 is implemented easily. If colonization by Legionella is demonstrated, surveillance with sputum cultures (and urinary antigen, if the $L$ pneumophila in the water is serogroup 1) could be initiated for every case of hospitalacquired pneumonia. If no cases of legionnaires' disease were uncovered in a 2- to 3-year period, then this outcome must be published and would support the CDC's position.

On the other hand, if cases of legionnaires' disease are discovered within 2 to 3 years, patient lives will have been saved, and the negative publicity in the lay media and the expensive litigation that accompanies an outbreak of hospital-acquired legionnaires' disease will have been avoided. Equally importantly, these data would add to the accumulating evidence that colonization of hospital water supplies presages clinical infections among inpatients. Such a study would contribute to resolving a debate that, given the high case-fatality rate of hospital-acquired legionnaires' disease, must be considered one of the most important unsettled issues in infection control today.

\section{REFERENCES}

1. Kool JL, Fiore AE, Kioski CM, Brown EW, Benson RF, Pruckler JM, et al. More than 10 years of unrecognized nosocomial transmission of legionnaires' disease among transplant patients. Infect Control Hosp Epidemiol 1998;19:898-904.

2. Lepine L, Jernigan DB, Butler JC, Pruckler JM, Benson RF, Kim F, et al. A recurrent outbreak of nosocomial legionnaire's disease detected by urinary antigen testing: evidence for long-term colonization of a hospital plumbing system. Infect Control Hosp Epidemiol 1998;19:905-910.

3. Evans AS. Causation and disease: the Henle-Koch postulates revisited. Yale J Biol Med 1998;49:175-195.

4. Best M, Yu VL, Stout J, Goetz A, Muder RR, Taylor F. Legionellaceae in the hospital water supply-epidemiological link with disease and evaluation of a method of control of nosocomial legionnaires' disease and Pittsburgh pneumonia. Lancet 1983;2:307-310.

5. Johnson JT, Yu VL, Best M, Vickers RM, Goetz A, Wagner R, et al. Nosocomial legionellosis uncovered in surgical patients with head and neck cancer: implications for epidemiologic reservoir and mode of transmission. Lancet 1985;2:298-300.

6. Yu VL. Nosocomial legionellosis: current epidemiological issues. In: Schwartz M, Remington J, eds. Current Clinical Topics in Infectious Disease. New York, NY: McGraw-Hill; 1986.

7. Chow J, Yu VL. Legionella: a major opportunistic pathogen in transplant 
recipients. Semin Respir Infect 1998;13:132-139.

8. Patterson WJ, Hay J, Seal DV, McLuckie JC. Colonization of transplan unit water supplies with Legionella and protozoa: precautions required to reduce the risk of legionellosis. J Hosp Infect 1997;37:7-17.

9. Allegheny County Health Department. Approaches to Prevention and Control of Legionella Infection in Allegheny County Health Care Facilities. 2nd ed. Pittsburgh, PA: Allegheny County Health Department; 1997: $1-15$.

10. Yu VL, Beam TR, Lumish RM, Vickers RM, Fleming J, McDermott C, et al. Routine culturing for Legionella in the hospital environment may be good idea: a three-hospital prospective study. Am J Med Sci 1987;294: 97-99.

11. Joly J, Alary M. Occurrence of nosocomial legionnaires' disease in hospitals with contaminated potable water supply. In: Barbaree JD, Breiman RF, Dufour AP, eds. Current Status and Emerging Perspectives. Washington, DC: American Society of Microbiology 1994;39.

12. Modol JM, Pedro-Botet ML, Sabria M, Gimeno JM, Prats R, Nieto J, et al. Environmental and clinical legionellosis in hospitals in Catalonia, Spain. Presented at the 38th Interscience Conference on Antimicrobial Agents Chemotherapy; September 1998; San Diego, CA. Abstract \#K$490 \mathrm{~A}$.

13. Second Report of the Committee of Inquiry Into the Outbreak of Legionnaires' Disease in Stafford in April 1985, London, England. Her Majesty's Stationery Office (HMSO); 1987.

14. Alary M, Joly JR. Factors contributing to the contamination of hospital water distribution systems. J Infect Dis 1992;165:565-569.

15. Vickers RM, Yu VL, Hanna SS, Muraca P, Diven W, Carmen N, et al Determinants of Legionella pneumophila contamination of water distribution systems: 15-hospital prospective study. Infect Control 1987;8: 357-363.

16. Marrie TJ, Green T, Burbridge S. Legionellaceae in the potable water of Nova Scotia hospital and Halifax residences. Epidemiol Infect 1994;112:143-150.

17. Arnow PM, Weil D, Para MF. Prevalence and significance of Legionella pneumophila contamination of residential hot-tap water systems. J Infect Dis 1985;152:145-151.

18. Butler JC, Fields BS, Breiman RF. Prevention and control of legionellosis. Infect Dis Clin Pract 1997;6:458-464.

19. Centers for Disease Control and Prevention. Guidelines for prevention of nosocomial pneumonia. MMWR 1997;46:31-34.

20. Tobin JO, Swann RA, Bartlett CLR. Isolation of L pneumophila from water systems: methods and preliminary results. BMJ 1981;282:515-517. 21. Dennis PJ, Taylor JA, Fitzgeorge RB, Bartlett CLR, Barrow GI. Legionella pneumophila in water plumbing systems. Lancet 1982;2: 949-951.

22. Marrie TJ, Macdonald S, Clarke K, Haldane D. Nosocomial legionnaires' disease: lessons from a four-year prospective study. Am J Infect Control 1991;19:79-85.

23. Wadowsky RM, Yee RB, Mezmar L, Wing EJ, Dowling J. Hot water systems as sources of Legionella pneumophila in hospital and nonhospital plumbing fixtures. Appl Environ Microbiol 1982;43:1104-1110.

24. Rudin J, Wing E. Prospective study of pneumonia: unexpected incidence of legionellosis. South Med J 1986;79:417-419.

25. Green M, Wald ER, Dashefsky B, Barbadora K, Wadowsky RM. Field inversion gel electrophoretic analysis of Legionella pneumophila strains associated with nosocomial legionellosis in children. J Clin Microbiol 1996;34:175-176.

26. Tkatch LS, Kusne S, Irish WD, Kristofiak S, Wing E. Factors affecting mortality for Legionella pneumonia at a university hospital. Presented at the 35th ICAAC annual meeting; September 1995; San Francisco, CA. Abstract 279.

27. Yu VL, Breiman RF. Point-counterpoint: surveillance cultures for Legionella. Presented at the 6th annual meeting of the Society for Healthcare Epidemiology of America; April 1996; Washington, DC. LaCrescenta, CA: Audio Archives; \#I60421-090, Symposium IV Compromised Hosts (audiotape)

28. Goetz AM, Stout JE, Jacobs SL, Fisher MA, Ponzer RE, Drenning S, et al. Nosocomial legionnaires' disease discovered in community hospitals following cultures of the water system: seek and ye shall find. Am J Infect Control 1998;26:6-11.

29. Stout JE, Lin Y-SE, Goetz AM, Muder RR. Controlling Legionella in hospital water systems: experience with the superheat-and-flush method and copper-silver ionization. Infect Control Hosp Epidemiol 1998;19: 911-914.

30. Lin YE, Vidic RD, Stout JE, Yu VL. Legionella in water distribution systems. Journal of the American Water Works Association 1998;90:112-121.

31. Liu WK, Healing DE, Yeomans JT, Ellioit TSJ. Monitoring of hospital water supplies for Legionella. J Hosp Infect 1993;24:1-9.

32. Muder RR, Yu VL, McClure J, Kominos S. Nosocomial legionnaires' disease uncovered in a prospective pneumonia study: implications for underdiagnosis. JAMA 1983;249:3184-3188. 